\title{
Economic Implications of Stigma and Discrimination in Nigeria (Case Study of Clients on Antiretroviral Treatment at the University Of Abuja Teaching Hospital Gwagwalada Abuja)
}

\author{
Abraham, A. D ${ }^{1}$, Amassoma, D ${ }^{2}$ \\ ${ }^{1}$ Consultant ActionAid Abuja, \\ ${ }^{2}$ Department of Economics, Adeleke University, Ede Osun State, Nigeria.
}

\begin{abstract}
Stigma and discrimination occurs in part due to myths that surrounded the modes of contracting HIV and the lack of law in place to respect, protect and fulfill the rights of the people with HIV/AIDS resulting in high incidence of new HIV infections especially among the economically productive persons between the ages 15 to 45 years old. Hence, these negative attitudes often delay and create fears in people to go for counseling and testing to know their HIV status which will inform better lifestyles and behaviors that are consistent with individuals HIV status; and hinders persons who are positive from utilization of available preventive programmes to protect them from re-infection. The study utilized both primary and secondary data and adopted factor analysis and descriptive statistics for the analysis. The findings revealed that about $47 \%$ of new HIV infections occurred due to stigma and discrimination while about 100 out of a thousand of people with HIV/AIDS loss their jobs for the same reason. The study hereby recommended that the federal government should pass into law the anti-stigma bill in order to respect, protect and fulfill the rights of the people living positive and criminalize any culprit and also implement the 15\% Abuja Declaration for more funds for HIV/AIDS intervention and to achieve zero new HIV infection.
\end{abstract}

\section{Introduction}

Human Immunodeficiency Virus and Acquired Immunodeficiency Syndrome (HIV/AIDS) is responsible for the deaths of over two million people yearly in sub-Saharan Africa, a figure greater than the number of lives lost to wars, famines and floods (UNAIDS, 2001). The National HIV/AIDS Response and Review, (2009) argues that nearly two and a half decades of the emergence of the HIV/AIDS as a significant public health challenge in Nigeria has become a generalized and matured epidemic affecting all population groups and geographic areas of the country. No wonder Gaffeo, (2003) opined that HIV/AIDS epidemic has remained a continuing, persistent and dangerous menace to the achievement of future national development targets including the Millennium Development Goals (MDGs) thus contributing to the reversal of some hardwon development gains of the recent past and playing essential roles in decreasing life expectancy at birth and worsening national health systems and care indicators. For instance, in 1985 Nigeria had only a case of HIV positive person reported in the United Nations General Assembly on Special Session (UNGASS) the same year; but due to lack of immediate action and funding of the HIV programme by government and other stakeholders the figure rose to 1.8 percent in 1991 and skyrocketed to 5.8 percent in 2001; the HIV prevalence declines to 5.0 percent in 2003 and further decreases to 4.4 percent in 2005, rise to 4.6 percent in 2008 the last survey was done 2010 with prevalence of 4.1 NACA, (2010). The corollary was almost getting out of hand with the loss of huge human capital resources; decline in the GDP; fall in the GDP per capita income; sudden rise in the orphaned children; increase in the number of youth and children out of school; upsurge in children headed households and fall in the standard of living that Nigeria government under the president Olusegun Obasanjo set up in 2000 National Action Committee for the Control of AIDS; but for a comprehensive intervention of HIV programme and to ensure a budget line the Committee was transformed to Agency the following year. More importantly, the buck of funding of the HIV/AIDS intervention is heavily depended on donor organizations leaving over 1.5 million eligible people including children in urgent need of antiretroviral treatment without access to treatment. The 1.5 million Nigerians could not access treatment because the donor organizations have met their target while inadequate funding limits government hospitals to accommodate additional clients as those who visited the public hospitals are turned down for lack of beds to admit them. As a result of over dependence on donor organizations for the funding of the HIV/AIDS intervention programmes put at $75 \%$ of the total resources there are over 1000 new HIV infections yearly observed by Idoko, (2012). Another major factor contributing to the spread of new infections is stigma and discrimination with its resultant economic implications on the already impoverished people who are either infected or affected by the epidemic; and the economy at large which is the focus of this current study. Stigma and discrimination occurs in part due to myths that surrounded the modes of 
contracting HIV and the lack of law in place to respect, protect and fulfill the rights of the people with HIV/AIDS resulting in high incidence of new HIV infections especially among the economically productive persons between the ages 15 to 45 years old. Hence, these negative attitudes often delay and create fears in people to go for counseling and testing to know their HIV status which will inform better lifestyles and behaviors that are consistent with individuals HIV status; and hinders persons who are positive from utilization of available preventive programmes to protect them from re-infection.

The remaining part of this paper would be structured into the following; section two incorporates the literature review, theoretical foundation and empirical review respectively. While section three entails the research methodology. Section four showcases empirical analysis and their discussion and section five concludes and proffers policy recommendations.

\subsection{Literature Review}

\section{Literature Review and Theoretical Foundation}

HIV/AIDS has created new opportunities for the manifestation of stigma and discrimination to people who are infected with and affected by epidemic according to Erving (1963). HIV related stigma refers to all unfavorable attitudes, beliefs, and policies directed toward people perceived to have HIV/AIDS as well as their loved ones, close associates, social groups, and communities; he further opined that the patterns of prejudice, which include devaluing, discounting, discrediting, and discriminating against these groups of people, play into and strengthen existing social inequalities especially those of gender, sexuality, and race that are at the root of HIV related stigma. Assuredly, stigma related to HIV/AIDS appears to be more severe than that associated with other life-threatening health conditions as put by (Songwathana \& Manderson, 2001). Sequel to the above, Brooks et al, (2005) observed that notable successes though have been recorded in both the prevention and treatment of HIV, but stigma and discrimination have been intractable problems associated with the AIDS epidemic throughout the world. Brooks et al, 2005 assert that stigma certainly has well-established individual consequences: it has been shown to delay HIV testing, restrict utilization of preventative programs, and hinder the adoption of preventative behaviors like condom use and HIV status disclosure. Furthermore, stigma has consequences for individual economic well-being as well as broader socioeconomic development that go beyond the impact of HIV disease alone. Perceived stigma and discrimination have been associated with increased prevalence and severity of depression among people living with HIV most often discussed at the individual level. Here, people living with HIV/AIDS (PLHA) are differentially treated by friends, family members and other individuals in one-on-one encounters. For example, friends may no longer be willing to associate with PLHA for fear of infection or accusations of also being infected. Family members may no longer feel comfortable sharing dishes, bathroom, kitchen, bed, drinking caps, cutleries or towels for fear of infection. Individuals living positive to HIV/AIDS in various countries in Asia have reported coercion to move from their homes by landlords and refusal of service at food and other business establishments (Human Rights Watch, 2003; Paxton et al., 2005). Regardless of whether stigma is experienced or perceived, it can have detrimental impacts on the individual thus; individuals who believe they will experience discrimination may be less willing to disclose their HIV positive status thereby limiting their access to resources for much-needed medical care and social support. Numerous studies have shown that PLHA suffering from discrimination are more likely to experience depression (Heckman et al., 2004; Joseph \& Bhatti, 2004; Manopaiboon et al., 1998). In turn, chronic depression among individuals with HIV hastens disease progression and resulted to premature mortality (Ickovics et al., 2001; Major\& O'Brien, 2005). Similarly, studies carried out in India, Vietnam, and Thailand revealed that fear of stigma led PLHA to quit their jobs and move to new communities should their HIV status become known; and likely to spread the HIV infection among the people in their host community according to (Bharat, 2001; ICRW, 2004; Songwathana \& Manderson, 2001). To buttress the foregoing, studies done in Nigeria unraveled that an HIV person who resides in Damaturu the capital of Yobe State however access antiretroviral treatment in the teaching hospital in Kaduna state although the same health services for the treatment of HIV are available in Yobe state where he lives and works. But, he chose to access health care services in Kaduna so as to avoid stigma and discrimination from his immediately environment (ActionAid Nigeria, 2011). Furthermore studies carried out by (Bharat, 2001; Human Rights Watch, 2003; ICRW, 2004; Joseph \& Bhatti, 2004; Kumarasamy et al., 2005; Paxton et al., 2005) have shown that individuals who have disclosed their HIV status to their families have been excluded from family events, prevented from having contact with the children in the family, cut off from the family's financial support and even forced to leave family residences in some critical instances. Similarly, in Vietnam it was reported that health care staff refused to provide injection services to PLHA for fear of infection (ICRW, 2004). This study also reported that hospital staff used separate medical devices to perform procedures on PLHA; when these devices could not be purchased or borrowed from other departments, individuals were denied these procedures. Studies in China, Thailand and the Philippines found that HIV positive patients were forced to wait for surgical procedures until those without infectious diseases had been treated (Yang et al., 2005; Ortega et al., 2005; Sringernyuang, Thaweesit and 
Nakapiew, 2005). In India, a growing number of private health care facilities have agreed to treat patients with HIV, however, staff wear at least one extra pair of gloves, use "AIDS kits," and fumigate operating and delivery rooms after they have been used stated by (Bharat, 2001). Over and above all, further studies have also unearthed other forms of stigma and discrimination which among others include noting patient charts or rooms with identifiable markers indicating the individual is HIV positive, requiring repeated HIV testing at the patients' expense, refusal of admission to hospital or clinics, being denied treatment, and experiencing delays in receiving treatment (Yang et al., 2005; Elamon, 2005; Khoat et al., 2005; Bharat, 2001; Songwathana and Manderson, 2001).In the vein, many Asian countries and Sub-Sahara Africa, sending family members abroad is an important means by which families increase household income due to limited economic opportunity or lowwage employment in local communities. For instance, countries such as the Philippines and Sri Lanka, remittances from overseas migrant workers constitute a vital source of foreign exchange earnings. Families from economically depressed communities rely on remittances as one of their primary sources of income. Refusal of entry or deportation due to one's HIV status not only denies one's right to work but also has a negative impact on a family economic well-being according to Songwathana and Manderson, (2001). Similarly, harassment of children in school as well as discriminatory attitudes and practices of teachers (e.g., segregation within the classroom) undermine the educational process of children living with or affected by HIV thereby limiting their capability set for future employment opportunities asserted by Bharat, (2001).

\subsection{Theoretical Foundation}

Studies in different countries in Africa and beyond revealed countries that had shown great political commitment and strong government support with less dependence on donor bodies have succeeded in reducing HIV/AIDS to a bearable level with zero new HIV infection Yang et al., 2005; Ortega et al., (2005). Furthermore, some of these African countries have anti stigma law in place that respects, protects and fulfills the rights of the people living with HIV/AIDS: Nigeria is yet to pass the anti stigma bill into law in order to respect, protect and fulfill rights of the people living with the HIV/AIDS. For example, the experience of Uganda and Thailand where the governments of each country prioritize prevention strategies for HIV/AIDS in critical areas; provided more public resources to HIV/AIDS programmes, and also provided supports to improve the implementation, monitoring and evaluation thereby mainstreaming the management of HIV/AIDS in almost all the sectors of their economy thus suggest that high level of political commitment and strong government support are capable of reducing HIV/AIDS prevalence in any developing country UNDP, (2002) with less dependence on the donor organizations' funding. Also in Botswana, the government took a similar stance in the fight against HIV/AIDS to that of Thailand and Uganda recorded tremendous reduction in the HIV/AIDS UNDP, (2002). This was achieved not only by getting the government to prioritize prevention strategies for HIV/AIDS in critical areas and providing more public resources to HIV/AIDS programmes, but also by providing support to improve the implementation, monitoring and evaluation thereby mainstreaming the management of HIV/AIDS in Botswana UNDP, (2002).

\subsection{Empirical Review}

Various studies around the world have shown that HIV/AIDS is indeed a public health problem. According to UNAIDS 2004 report, out of 34 to 46 million people globally infected with HIV/AIDS 25 to 28 million of them live in Africa although home only to $10 \%$ of the total world population making it extremely difficult if not impossible for the African continent to provide greater socioeconomic opportunities to her citizenry. In a study carried out by Veenstra and Whiteside (2005) they observed that the global spread of HIV/AIDS has brought with it the realization that the disease is more complex and extensive than imagined. They noted that the epidemic's alarming infection rate with cure out of sight has considerable social and economic consequences. One empirical result carried out showed that income received by affected households during the year 2000 was approximately 35 per cent lower than that received by unaffected households; per capita monthly income for the average affected household was about $31 \%$ lower than that of unaffected households as observed by (Wyss et al, 2004). The study brings to light changes in household expenditure patterns: health and medical care, transportation and funeral expenditure increased among affected households interviewed, while spending on education, housing and remittances was reduced. For example, affected households increased their transportation costs by $4.7 \%$ and reduced expenditure on education by $7.3 \%$ and housing by $11.5 \%$ (Wyss et al, 2004). There are also more indirect and long-term repercussions of the epidemic on households, that are not immediately apparent and that go beyond the economic sphere, such as grief and increasing stress, which can negatively influence the psycho-social state of children. HIV related illness also increases medical expenditures, putting further financial burden on the already impoverished household as opined by Muyinda and Seeley, (1997). The loss of income due to illness and premature death is intensified when an individual with HIV/AIDS or their family members are denied employment or dismissed from their jobs because of HIV status as some inherent economic implications on the infected and affected and to the 
society at large as observed by Muyinda and Seeley (1997). In Nigeria, over dependence on donor bodies fund for the HIV/AIDS interventions are major set-backs in achieving AIDS interventions, which is not only unsustainable but also places a ceiling on the number of the PLHA who have access to treatment, care and support from the donor referral centre since there are target to meet in a specified period of time by the donor bodies: this has left and denied over 1.5 million people including 212,720 children as of 2010 in dire need of treatment, care and support resulting in hasten the HIV progression leading to AIDS and untimely death due to limited funding of the healthcare sector on the part of government (Journalist Against AIDS, 2011). At the moment in Nigeria, donor bodies' fund for the HIV/AIDS interventions amounted to over 75\% of the total resources leaving the HIV/AIDS intervention programme at the mercy of donor bodies. Evidence from the above reviewed literatures depicted that HIV/AIDS has exhibited some forms of economic implications on the infected and affected people and to the economy at large. To confirm this, the study would take a step further to test empirically if of a truth there is an economic implication on the above subject matter. This takes us to the next section.

\subsection{Data Sources}

\section{Data Sources And Method}

In this research work qualitative data were collected by means of structured form of questions and indepth interview method to corroborate information gotten from the returned questionnaire. A total of 280 respondents were sampled from HIV/AIDS clients accessing treatment at the University of Abuja Teaching Hospital Gwagwalada Federal Capital Territory, Abuja. Using a simple random sampling technique out of which hundred and ninety four (194) that were dully completed was used for final analysis. On the other hand, the secondary data were obtained from academic journals, briefs textbooks, articles and publications and reports of the Non-Governmental Organizations including UNDP, UNAIDS, NACA, WHO, AAN to mention few.

\subsection{Methodology}

This study adopted both factor analysis and descriptive statistics to investigate the economic implications of stigma and discrimination against the people living positive to HIV/AIDS. Furthermore, the Cronbach alpha coefficient was employed to test the reliability and validity of the research instruments. The generated data was analyzed by employing the statistical software package called an Integrated Statistical Package 12 (STATA 12).

\subsection{Description of the Study Area}

\section{Empirical Analysis And Discussion Of Results}

The study was carried out in Federal Capital Territory Gwagwalada Area Council Nigeria at University of Abuja Teaching Hospital special clinic. Gwagwalada is one of the five Area Councils of the Federal Capital Territory of Nigeria together with Abaji, Kuje, Bwari and Kwali; the FCT also includes the City of Abuja. Gwagwalada is located at the middle belt religion of Nigeria; it is approximately between latitude $8.9483889^{\circ}$ and longitude $7.091944^{\circ}$ with sunrise at 06:21 and sunset of 18:31. Gwagwalada has an area of $1,043 \mathrm{~km}^{2}$ and a population of 157,770 at the 2006 census; the postal code of the area is 902 and the University of Abuja teaching hospital is located in Gwagwalada. Bordering the FCT are the states of Kaduna to the northeast, Plateau to the east and south, Kogi to the southwest, Niger to the west and northwest and Nasarawa to north.

\section{Presentation Of The Results And Discussion}

Table 1: Selected Socio-Demographic characteristics of the respondents

\begin{tabular}{|l|l|l|}
\hline Respondents' Residence & Frequency $\{\mathbf{N = 1 9 4 \}}$ & Percentage $\{\%\}$ \\
\hline Rural & 97 & 50 \\
\hline Urban & 97 & 50 \\
\hline Respondent's Sex & 70 & 36 \\
\hline Male & 124 & 64 \\
\hline Female & \multicolumn{2}{|l|}{} \\
\hline Respondent's Age & 5 & 2.58 \\
\hline $15-21$ & 40 & 20.62 \\
\hline $22-31$ & 89 & 45.88 \\
\hline $31-41$ & 41 & 21.13 \\
\hline $42-51$ & 19 & 9.79 \\
\hline 52 and above & \multicolumn{2}{|l|}{} \\
\hline Respondent's Marital status &
\end{tabular}




\begin{tabular}{|l|l|l|}
\hline Single & 38 & 19.59 \\
\hline Married & 96 & 49.48 \\
\hline Separated due to HIV\&AIDS & 20 & 10.31 \\
\hline Divorced due to HIV\&AIDS & 13 & 6.70 \\
\hline Widowed due to HIV\&AIDS & 26 & 13.40 \\
\hline Others & 1 & .52 \\
\hline Respondents' Educational Attainment & 32 & \multicolumn{2}{|l|}{} \\
\hline Primary & 87 & 16.49 \\
\hline Secondary & 17 & 44.85 \\
\hline Tertiary & 30 & 8.76 \\
\hline BSC. & 4 & 15.46 \\
\hline HND & 8 & 2.06 \\
\hline Vocational & 15 & 4.12 \\
\hline Quran & 1 & 7.73 \\
\hline Others & 15 & 0.52 \\
\hline Respondent's Occupation & 78 & 7.73 \\
\hline Farming & 27 & 40.21 \\
\hline Training & 30 & 13.92 \\
\hline Government worker & 38 & 15.46 \\
\hline Private company worker & 6 & 19.59 \\
\hline Unemployed & \multicolumn{2}{l|}{} \\
\hline Others & \multicolumn{2}{l|}{} \\
\hline
\end{tabular}

\section{Source: Author's Survey 2013}

In this section we begin with a brief overview of the study population with respect to several socioeconomic characteristics ties as presented in Table 1 above. Evidence from the results indicates that the residences of the respondents were evenly distributed. This is because half of the population emanated from rural while the other half were from urban area. Again, from the result output, it was discovered that approximately $64 \%$ of the affected population were females while the remaining were males $35 \%$. This shows that more females were affected than their males' counterparts. Furthermore, the result from the sociodemographic factors indicated that, approximately $88 \%$ of the overall population falls under the age bracket of the working population. This constitutes great implication to the economic growth of Nigeria which in the longrun might have induced poverty, social menace on the part of the family especially if the infected persons are breadwinners of their households. Some principal economic effects experienced by affected households are: loss of available income, as working adults falling ill or dying or having to stop work to look after children and/or the ill member of the household; additional expenditure on health care and funerals (UNAIDS, 2004). It was observed again from the table above that about $45 \%$ of the respondents only had secondary certificate, $26 \%$ had University education approximately $17 \%$ had primary education while others constituted about say $12 \%$ of the overall respondents. From the above, it could be deduced that the lower the level of education, the higher the tendency to be infected with HIV/AIDS and vice-versa all things being equal. This further implies that the extent of education acquired by individuals could inform better lifestyles and behaviors that will not dispose to HIV infection. Besides, it was discovered that the percentage of the respondents that were separated, divorced or widowed as a result of HIV/AIDS constituted about $30.1 \%$ of the overall respondents while approximately $69 \%$ of the infected are those that either married or single. Hence, we can infer that HIV/AIDS has a direct implication on the marital status all things being equal. The demographic characteristics also showed that about $20 \%$ of the respondents were unemployed while the remaining $80 \%$ were meaningfully engaged in productive economic activities. This further depicts that $20 \%$ of the respondent would have challenge in footing their medical bills since they are not working; however government provides the antiretroviral drugs free to HIV/AIDS clients, but other expenses namely, treatment of opportunistic infections, feeding, laboratory tests for CD-4 counts in order to know the viral load for the next line of regime patients are to be placed on and transportation to the hospital all of these expenses are borne by the HIV/AIDS clients. 
Table 2: Analysis Of Econmic Efffects Of New Hiv Infections As A Result Of Stigma And Discrimination

\begin{tabular}{|l|l|l|l|l|ll|}
\hline \multicolumn{1}{|c|}{ Stigma and discrimination } & Coef. & Std. Err. & $\mathbf{Z}$ & $\mathbf{P}>\mid \mathbf{z}$ & {$[\mathbf{9 5 \%}$ Conf. Interval] } \\
\hline $\begin{array}{l}\text { Variable13: Person(s) living with } \\
\text { HIV/AIDS }\end{array}$ & .0466 & .159677 & 0.29 & 0.770 & -.2663532 & .3595692 \\
\hline $\begin{array}{l}\text { Variable23: Loss of job due to } \\
\text { HIV/AIDS }\end{array}$ & $\begin{array}{l}1.000 \\
65\end{array}$ & .4135586 & 2.42 & 0.016 & .1900903 & 1.81121 \\
\hline $\begin{array}{l}\text { Variable26: Change residence } \\
\text { due to HIV/AIDS }\end{array}$ & - & .0007692 & - & 0.147 & -.0026242 & .0003909 \\
& $\begin{array}{l}.0011 \\
\text { Constant }\end{array}$ & & 1.45 & & & \\
& 1.268 & .6187369 & - & 0.040 & -2.481383 & -.0559793 \\
& 681 & & 2.05 & & & \\
\hline
\end{tabular}

\section{Source: Author's Survey 2013}

In the Table 2 above, variable13 represents the number of the people that are HIV positive; varibale23 is loss of job due to HIV/AIDS and varibale26 is change in residence due to stigma and discrimination. The study discovered that the spread of HIV/AIDS has a positive but insignificant effect via abuse from relatives, friends and the community. Although consistent with apriori expectations yet it portrayed an insignificant effect on the explanatory variables. This further implies that due to stigma and discrimination, new HIV infections increases by about $47 \%$ of the total population under consideration. Similarly, the result shows that when patient with the disease is stigmatized, about 100 out of a thousand loss jobs either as a result of termination from the employers or due to relocation to a new environment because of stigma and discrimination. However, the case of change of residence by an HIV/AIDS patient reduces by $-0.11 \%$ as a result but the coefficient of stigma is not statistically significant at $1 \%$ and $5 \%$ with regards to the influence of this variable on change of residence due to HIV/AIDS; only the impact of stigma on loss of job due to HIV/AIDS is statistically significant at $1 \%$ and $5 \%$ of alpha respectively.

\section{Conclusion and Recommendations}

In a nutshell, the study shows that stigma and discrimination contributes to the spread of new HIV Infections which confirms other studies carried out in other parts of the world. In addition, if federal government passes the anti stigma bill into law it will go a long way to reduce new HIV infection due to stigma and discrimination. It is however recommended that when all levels of government including the federal, state and local implement the 15\% Abuja Declaration which is to allocate the 15\% of the annual budget to the health sector will make more funds available for a comprehensive HIV/AIDS intervention programmes and also reduces dependence on donor organizations which at moment is over $75 \%$ of total resources use for HIV/AIDS. Furthermore, it is advisable that states that are yet to transform into agency the state action for the control of HIV/AIDS need to do so for a comprehensive HIV/AID intervention programme at the state and local council level respectively. Moreover, there is need for a strong political commitment at all levels of government when done it will bring about drastic reduction in over dependence on donor bodies for funding; provide treatment, care and support to millions of Nigerians in dire need of such programme interventions; reduce HIV/AIDS burdens both at micro and macro levels and in no distant time Nigeria will achieve zero tolerance and zero new HIV infection.

\section{References}

[1]. Ainsworth, M., Beyrer C. and Soucat A. (2003) "AIDS and Public Policy: The Lessons and Challenges of 'Success' in Thailand." Health Policy 64: 13-37.

[2]. Ainsworth, Martha, Chris Beyrer and Agnes Soucat (2000) "Thailand's Response To Aids: Building On Success, Confronting The Future." Thailand Social Monitor, V, World Bank, Washington, D.C.

[3]. Bell C, et al (2003) The Long-Run Economic Costs of AIDS: Theory and an Application to South Africa.

[4]. Cohen D (1997) Socio-economic Causes and Consequences of HIV epidemic in Southern Africa: a case study of Namibia. HIV and Development Programme Issues Paper No 31 UNDP

[5]. Daniel A.A (2011) HIV/AIDS counseling and testing training organized for staff of ActionAid Nigeria by the management of the organization

[6]. Greener, Robert (2002) “AIDS and Macroeconomic Impact," in Steven Forsythe, ed. State ofthe Art: AIDS and Economics, pp. 4955. International AIDS-Economics Network and The POLICY Project. http://www.policyproject.com/pubs/other/SOTAecon.pdf (accessed March 2008).

[7]. Jan Isaksen Nils Gunnar Songstad Arild Spissøy, (2002): Socio-economic effects of HIV/AIDS in African countries.

[8]. Martha Ainsworth Confronting the AIDS epidemic Setting Government Priorities in Preventing HIV/AIDS.

[9]. Mtika, M (2003): Family Transfers in a Subsistence Economy under a High Incidence of HIV/AIDS: The Case of Rural Malawi, Journal of Contemporary African Studies, Vol. 21, No. 1

[10]. National Agency for the Control of HIV/AIDS (2009): National AIDS Response Review (NACA).

[11]. Oni S.A.; Obi C.L; Okorie A; Thadebe D, Jordan A ( 2002): Economic Impact of HIV/AIDS on Rural Householder Smallholder Agricultural Production and Orphans in the Limpopo Province of South Africa. The South Africa Journal of Economics 70 (7)

[12]. Prof. John Idoko DG, (2012) National Action for the Control of AIDS in Nigeria Daily Trust Thursday August 16, 2012 
[13]. Stanislav Kolenikov (2006) University of Missouri Columbia, MO/USA: Confirmatory factor analysis pp- 2

[14]. UNAIDS (2002): Epidemiological Fact Sheets on HIV/AIDS and Sexually Transmitted Infections:South Africa. Geneva: UNAIDS.

[15]. UNAIDS, (1999): A review of household and community responses to HIV/AIDS epidemic in rural areas of Sub-Sahara Africa Geneva Switzerland.

[16]. University of Abuja Teaching Hospital Gwagwalada Federal Capital Territory Abuja, Special Clinic for the HIV/AIDS patients 2011.

[17]. Wyss, K., Hutton, G. \& N'Diekhor, Y (2004): Costs attributable to AIDS at household level in Chad. AIDS CARE. 16(7), 808-816.

[18]. Yamano, Takashi and T.S. Jayne (2002) "Measuring the Impacts of Prime-Age Adult Death on Rural Households in Kenya." Working Paper 5, Tegemeo Institute of Agricultural Policy and Development, Nairobi, Kenya.

[19]. Yamano,T., \& Jayne,T.S (2004) Measuring the impacts of working-age adult mortality on small-scale farm households in Kenya. World Development, 32(1), 91-119. 